\title{
Induced Pluripotent-stem-cell Related Genes Contribute to De-differentiation in Oral Squamous Cell Carcinoma
}

\author{
DAISUKE TAKEDA ${ }^{1}$, TAKUMI HASEGAWA ${ }^{1}$, TAKESHI UEHA2, EIJI IWATA ${ }^{1}$, \\ RISA HARADA ${ }^{2}$, AKIKO SAKAKIBARA ${ }^{1}$, TERUYA KAWAMOTO ${ }^{3}$, \\ TSUTOMU MINAMIKAWA ${ }^{1}$, YOSHITADA SAKAI ${ }^{2}$ and TAKAHIDE KOMORI ${ }^{1}$ \\ ${ }^{1}$ Departments of Oral and Maxillofacial Surgery, Kobe University Graduate School of Medicine, Kobe, Japan; \\ ${ }^{2}$ Departments of Rehabilitation Medicine, Kobe University Graduate School of Medicine, Kobe, Japan; \\ ${ }^{3}$ Departments of Orthopaedic Surgery, Kobe University Graduate School of Medicine, Kobe, Japan
}

\begin{abstract}
Background/Aim: Cancer stem cells are suspected to contribute to malignancy in tumors. Hypoxia affects cell differentiation and induces stem-cell-like characteristics in malignancies. Induced pluripotency was demonstrated in mouse fibroblasts by reprogramming with four transcriptional factors: Oct3/4, Sox2, c-Myc, and Klf4. Conversely, oncogenic transformations frequently express transcriptional factors and Nanog. Therefore, cancer cells present some similarities with induced pluripotent stem (iPS) cells. Materials and Methods: We investigated the expression of iPS-related genes in vitro and in clinical samples to identify their relationships with hypoxia and tumorigenesis. Results: Oral squamous cell carcinoma (SCC) cells were used to show that expression levels of Oct3/4, Sox2, and Nanog were significantly increased in hypoxic condition in vitro and in moderately- and poorly-differentiated samples. Conclusion: We propose that Oct3/4, Sox 2 and Nanog are associated with tumor hypoxia characterized in oral SCC and that these factors may also contribute to the undifferentiated potency observed in oral SCC clinically.
\end{abstract}

Oral squamous cell carcinoma (SCC) is representative of most oral malignancies. Oral SCC often presents with locoregional recurrences and distant metastases in developmental and/or recurrent cases, which are associated with poor patient prognosis. A key feature of the disease is a solid tumor possessing a low oxygen condition (hypoxia) (1).

Correspondence to: Takumi Hasegawa, D.D.S., Ph.D., Department of Oral and Maxillofacial Surgery, Kobe University Graduate School of Medicine, 7-5-1 Kusunoki-cho, Chuo-ku, Kobe 6500017, Japan. Tel: +81 783826213, Fax: +81 783826229, e-mail: hasetaku@med.kobe-u.ac.jp

Key Words: Squamous cell carcinoma, induced pluripotent stem cell, reprogramming factors, iPS-related genes, stemness factors.
Several reports highlight a relationship between hypoxia and cell differentiation (2-5). More specifically, hypoxia has been shown to down-regulate expression of differentiationspecific genes and induce stem-cell-like characteristics in malignancies $(6,7)$. Stem cells have been identified in the majority of tissues, therefore there is a new focus for stem cells in cancer biology (8). Cancer stem cells are suspected to contribute to tumor recurrence and resistance to chemoand/or radiation therapy (8). However, controversial findings exist around cancer stem cells with respect to malignant progression in oral malignancies.

Takahashi and Yamanaka have demonstrated that pluripotent stem cells can be directly generated from mouse embryonic or adult fibroblast cultures by induction of four transcriptional factors: octamer-binding transcription factor 3/4 (Oct3/4), sex determining region Y-box 2 (Sox2), cmyelocytomatosis viral oncogene (c-Myc), and Kruppel-like factor 4 (Klf4), under embryonic stem cell (ESC) culture conditions $(9,10)$. The generated cells are designated induced pluripotent stem (iPS) cells. Oncogenic transformations frequently contain de novo acquisitions of developmental programs, including unlimited proliferation and self-renewal, and the expression of transcriptional factors, such as Oct3/4, Sox2, c-Myc, Klf4, and Tir Na Nog (Nanog) (11). Therefore, cancer cells present some similarities with iPS cells and other reprogrammed stem cells. However, Takahashi and Yamanaka report that Nanog is dispensable for the generation of iPS cells. On the other hand, the possibility of iPS cell cancerization is reported (12), alongside a report that hypoxia enhances the generation of iPS cells (13). Stability of the hypoxic condition is thought to induce expression of Oct3/4, Sox2, and Nanog via activated hypoxia-inducible factors in cancer cells $(14,15)$. Based on these findings, we believe a relationship exists between hypoxia, iPS-related genes, and tumorigenesis. Although expression of each iPS -related gene is reported in various clinical cancer studies, their combined expression in oral SCC remains to be elucidated. 
Based on these reports, we hypothesized that iPS-related genes would affect malignant progression regarding hypoxia, differentiation, and prognosis in oral SCC. In this study, we investigated iPS-related gene expression in oral SCC cells in vitro under normoxic and hypoxic conditions, and between normal mucous membranes and cancerous tissues obtained from patients with oral SCC.

\section{Materials and Methods}

Cell culture and experiments. The oral cancer cell line HSC-3 was obtained from the Health Science Research Resources Bank (Osaka, Japan). HSC-3 cells were suspended in Eagle's Minimum Essential Medium (Sigma-Aldrich, St Louis, MO, USA) supplemented with $10 \%$ fetal bovine serum (Sigma-Aldrich) and 1000 units $/ \mathrm{mL}$ penicillin/streptomycin solution (Sigma-Aldrich) and cultured in a $5 \% \mathrm{CO}_{2}$ incubator at $37^{\circ} \mathrm{C}$. Trypsin $(0.25 \%)$ in ethylenediaminetetraacetic acid $(0.02 \%$; Sigma-Aldrich) solution was used to isolate cells as previously described (16). To investigate different oxygen conditions on the expression of iPS-related genes, we seeded $1.0 \times 10^{7}$ cells into 6 -well plates (normoxic condition) or $15 \mathrm{ml}$ tubes (pellet culture: hypoxic condition), and cultured them for 7 days. After incubation, total RNA was extracted from each cell culture.

Patients and clinical specimens. Twenty-five patients with oral SCC were enrolled in this study. Patients underwent surgical excision at the Department of Oral and Maxillofacial Surgery, Kobe University Hospital from October 2012 to June 2014. Their clinical and pathological characteristics were retrospectively obtained from hospital records. All participating patients received clinical treatment according to consensus guidelines for head and neck cancers. For each patient, we performed a surgical excision with a clear 10-mm margin from the tumor edge using the intraoperative frozen section procedure. All tumor specimens were independently examined by two experienced pathologists. For each patient, an adjacent sample of mucous membrane of the same origin as the primary tumor was excised during surgery (17). Both specimens were immediately frozen and stored at $-80^{\circ} \mathrm{C}$ until total RNA extraction. The Ethics Committee of Kobe University Hospital approved this study (permission number: 1302) and informed consent was obtained from all patients.

Quantitative real-time polymerase chain reaction (PCR). Quantitative real-time PCR was performed to analyze mRNA expression of the iPS-related genes in cells and clinical specimens. Total RNA was extracted using an RNeasy Mini Kit (Qiagen, Valencia, CA, USA). cDNA was synthesized (200 ng of total RNA) using a High Capacity cDNA Transcription Kit (Applied Biosystems, Foster City, CA, USA). Quantification of mRNA transcription was performed using an Applied Biosystems StepOne Real-Time PCR System (Applied Biosystems). Real-time PCR reactions $(20 \mu \mathrm{l})$ contained $0.1 \mu \mathrm{l}$ forward primer, $0.1 \mu \mathrm{l}$ reverse primer, $1 \mu \mathrm{L}$ of cDNA template from RT reaction, and $10 \mu \mathrm{l}(2 \times)$ master mix for Power SYBR green master mix (Applied Biosystems). Reaction conditions were performed as previously reported (16).

All primers were custom-made and purchased from Invitrogen (Carlsbad, CA, USA). Primer sequences were designed as follows: for GAPDH: forward (5'-TTG GTA TCG TGG AAG GAC TCT A3') and reverse (5'-TGT CAT ATT TGG CAG GTT-3'), for Oct3/4: forward (5'-CGT GAA GCT GGA GAA GGA GAA GCT-3') and reverse (5'-CAA GGG CCG CAG CTT ACA CAC ATG TT-3'), for Sox2: forward (5'-AAG AGA ACA CCA ATC CCA TCC A-3') and reverse (5'-AGT CCC CCA AAA AGA AGT CCA-3'), for $c-M y c$ : forward (5'-AAG GCT CTC CTC TGC TTA G-3') and reverse (5'CTC TCC TCG TCG CAG TAG AAA TAC-3'), for Klf4: forward (5'-GGA CAT CAA CGA CGT GAG C-3') and reverse (5'-GAC GCC TTC AGC ACG AAC-3'), and for Nanog: forward (5'-AGT AAA GGC TGG GGT AGG TAG G-3') and reverse (5'-GAA CTC TCC AAC ATC CTG AAC C-3') $(18,19)$.

Statistical analysis. Expression level of each target gene was normalized to the $\beta$-actin level using the $\Delta \Delta C T$ method; (Applied Biosystems). Data are presented as mean values \pm standard error. Significance of differences between mean values was evaluated by Student's $t$-test. The level of statistical significance was set at $p<0.05$.

\section{Results}

Clinical and pathological characteristics of SCC patients. Patient clinical and pathological characteristics are summarized in Table I. From a total of 25 patients, 14 were males $(56.0 \%)$ and 11 were females $(44.0 \%)$, with a mean age of 69.3 years (range: $39-88$ years). The most common primary sites were upper gingiva $(24.0 \%)$ and buccal mucosa (24.0\%), followed by tongue (20.0\%), lower gingiva $(20.0 \%)$, and oral floor (12.0\%). Pathological T classifications were $\mathrm{T} 1$ in 2 patients $(8.0 \%), \mathrm{T} 2$ in 11 patients (44.0\%), T3 in 3 patients $(12.0 \%)$, and $\mathrm{T} 4$ in 9 patients $(36.0 \%)$. Pathological types were grade 1 in 15 patients (60.0\%), grade 2 in 8 patients $(32.0 \%)$, and grade 3 in 2 patients $(8.0 \%)$. Pathological Yamamoto-Kohama mode of invasion (YK) classifications were YK-3 (groups of cells with no distinct borderline) in 17 patients $(68.0 \%)$ and YK4C (diffuse cord-like invasion) in 8 patients $(32.0 \%)$. Total pathological TNM stages were I in 2 patients ( $8.0 \%)$, II in 8 patients $(32.0 \%)$, III in 4 patients $(16.0 \%)$, IVA in 7 patients (28.0\%), and IVB in 4 patients (16.0\%). Disease control status in June 2016 was local recurrence in 4 patients $(16.0 \%)$, neck recurrence in 3 patients (12\%), locoregional recurrence in 1 patient (4\%), distant metastasis in 1 patient $(4 \%)$, and death from disease in 5 patients $(20 \%)$.

Expression levels of iPS- related genes in clinical oral SCC samples. Quantitative real-time PCR showed that mRNA expression levels of Oct3/4, Sox2, c-Myc, Klf4, and Nanog were $1.0 \pm 0.25,1.0 \pm 0.19,1.0 \pm 0.17,1.0 \pm 0.24$, and $1.0 \pm 0.29$ in well-differentiated samples, and $3.7 \pm 1.0,2.6 \pm 0.64$, $1.1 \pm 0.34,1.1 \pm 0.30$ and $4.6 \pm 1.2$ in moderately- and poorlydifferentiated samples from cancerous tissues relative to normal tissues, respectively (Figure 1A-E). mRNA expression levels of Oct3/4, Sox2, and Nanog were significantly higher in moderately- and poorly-differentiated samples than in well-differentiated samples $(p<0.05)$. 
Table I. Clinical and pathological characteristics of 25 patients with oral squamous cell carcinoma.

\begin{tabular}{lc}
\hline Characteristics & No. of patients $(\%)$ \\
\hline Age and gender & $25(100 \%)$ \\
Age & \\
Mean: 69.3 years & Range: $39-88$ years \\
Gender & \\
Male & $14(56 \%)$ \\
Female & $11(44 \%)$ \\
Tumor site & \\
Tongue & $5(20 \%)$ \\
Upper gingiva & $6(24 \%)$ \\
Lower gingiva & $5(20 \%)$ \\
Oral floor & $3(12 \%)$ \\
Buccal mucosa & $6(24 \%)$ \\
Pathological T classification & \\
1 & $2(8 \%)$ \\
2 & $11(44 \%)$ \\
3 & $3(12 \%)$ \\
4 & $9(36 \%)$ \\
Pathological grade (WHO) & \\
1 & $15(60 \%)$ \\
2 & $8(32 \%)$ \\
3 & $2(8 \%)$ \\
Pathological YK classification & \\
3 & $17(68 \%)$ \\
4C & $8(32 \%)$ \\
Total pathological TNM stage & \\
I & $2(8 \%)$ \\
II & $8(32 \%)$ \\
III & $4(16 \%)$ \\
IVA & $7(28 \%)$ \\
Disease control status & $4(16 \%)$ \\
Local recurrence & \\
Neck recurrence & $4(16 \%)$ \\
Locoregional recurrence & $3(12 \%)$ \\
Distant metastasis & $1(4 \%)$ \\
Death from disease & $1(4 \%)$ \\
\hline
\end{tabular}

Subgroup analysis of prognosis with expression levels of iPS-related genes in clinical oral SCC samples. Quantitative real-time PCR showed that mRNA expression levels of Oct3/4, Sox2, c-Myc, Klf4, and Nanog were $1.0 \pm 0.98$, $1.0 \pm 1.1,1.0 \pm 1.2,1.0 \pm 1.0$ and $1.0 \pm 0.82$ in disease-free samples, and $1.5 \pm 0.48,1.2 \pm 0.34,0.6 \pm 0.13,1.2 \pm 0.27$ and $1.4 \pm 0.42$ in samples from recurrence and death from disease patients, respectively (Figure 2A-E). There was no significant relationship between prognosis and expression of iPS-related genes.

Effect of oxygen level on mRNA expression of iPS-related genes in oral SCC cells in vitro. Quantitative real-time PCR showed that relative mRNA expression levels of Oct3/4,
Sox2, c-Myc, Klf4, and Nanog were 1.0 $\pm 0.13,1.0 \pm 0.095$, $1.0 \pm 0.17,1.0 \pm 0.088$, and $1.0 \pm 0.11$ in normoxic condition, and $2.9 \pm 0.55,1.6 \pm 0.095,0.85 \pm 0.044,2.0 \pm 0.59$, and $3.7 \pm 0.81$ in hypoxic condition, respectively (Figure 3A-E). mRNA expression levels of Oct3/4, Sox2, and Nanog were significantly higher in hypoxic condition than in normoxic condition (Sox2: $p<0.01$, Oct3/4 and Nanog: $p<0.05$ ).

\section{Discussion}

Oral SCC is categorized as a solid tumor that possesses low oxygen condition as one of its key features (1). Hypoxia inhibits differentiation of cytotrophoblast cells and kidney epithelial cell lines $(2,3)$, is associated with differentiation in clinical uterine cervix SCC cells (4), and reduces differentiation in prostate cancer cell lines (5). Furthermore, hypoxia down-regulates expression of differentiation-specific genes and induces stem-cell-like characteristics in neuroblastoma cell lines (6) and clinical ductal breast cancer cells (7). These reports indicate that hypoxia affects tumor cell differentiation status and promotes dedifferentiation. Stem cells are currently defined in most tissues and tumorigenic cancer cells are recognized to have similarities with normal stem cells. Therefore, stem cell biology has refocused into cancer biology (8). Induced pluripotency was first demonstrated in mouse fibroblasts by reprogramming with four transcriptional factors (reprogramming factors): Oct $3 / 4$, Sox2, c-Myc, and Klf4, whereas Nanog is now known to be dispensable (9). On the other hand, the possibility of iPS cell cancerization has been suggested (12), and that Nanog is often expressed in various malignancies thus has a critical function in cancer stem cell subpopulations (11). Tumorigenesis is therefore thought to be related not only to initial reprogramming factors, but also to Nanog (iPS-related genes; a stemness factor). In this study, we examined expression levels of iPS-related genes in vitro and in clinical samples to understand stemness factors in oral SCC.

Oct $3 / 4$ is a nuclear protein and regulates the self-renewal and differentiation in ESCs (20). Nanog is a downstream target of Oct $3 / 4$ and contributes to cell fate determination of the pluripotent inner cell mass and maintains the self-renewal capacity in ESCs with Oct3/4 $(21,22)$. Expression of Oct3/4 and Nanog can cause dysplasia, which in turn, leads to carcinoma in epithelial cells and is associated with poor prognosis in malignancies including oral SCC $(20,21)$ and lung adenocarcinoma (22). Nanog expression is reported to be an independent prognostic factor for patients with esophageal SCC (23). It is also suggested that Nanog promotes SCC formation, acting as a cell autonomous activator of epithelial-mesenchymal-transition in epithelial cells (24), and that its expression is thought to be correlated with malignancy and chemoresistance (25). Sox 2 is also a 


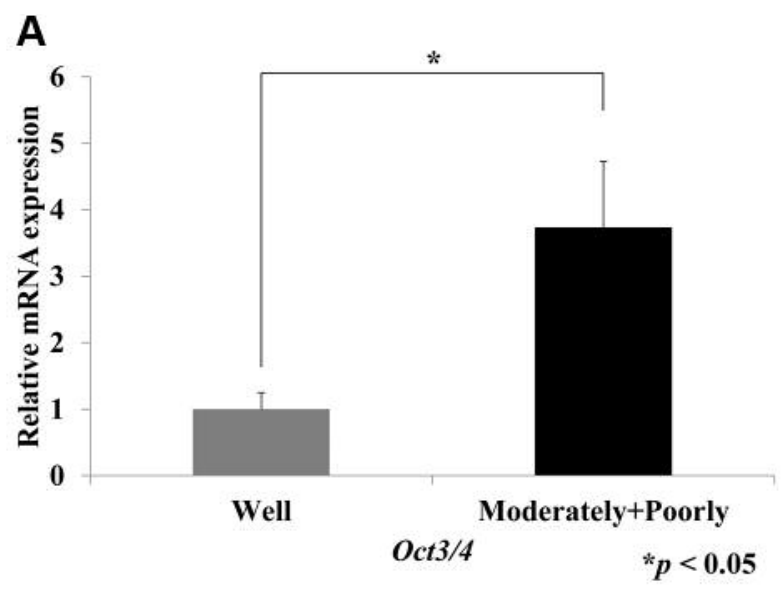

B
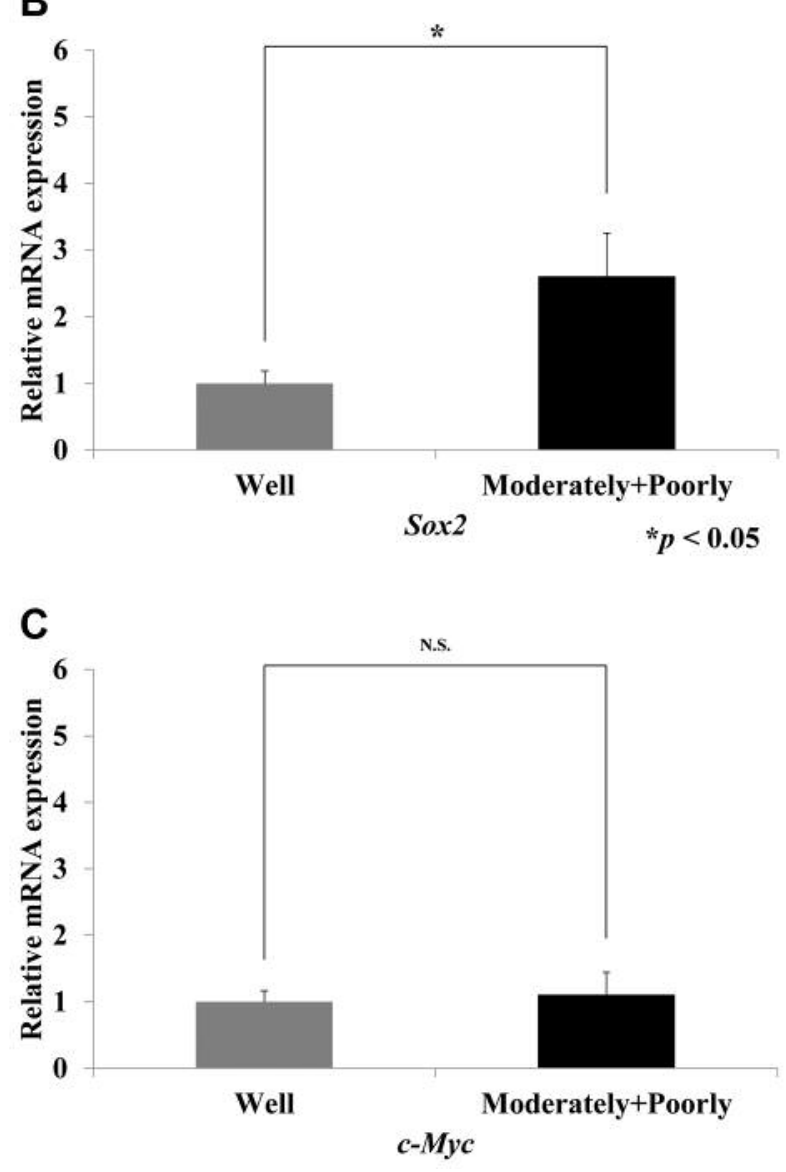

pluripotency-associated transcription factor and regulates cell fate with Oct3/4 and Nanog in ESCs. It is suggested that expression of Sox 2 correlates with tumor recurrence and poor prognosis in head and neck SCC (26), esophageal SCC (27), and breast carcinoma (28). $C$ - $M y c$ is a proto-oncogene consisting of L-myc and N-myc. C-Myc functions by acting on cell cycle progression, cell growth and differentiation,
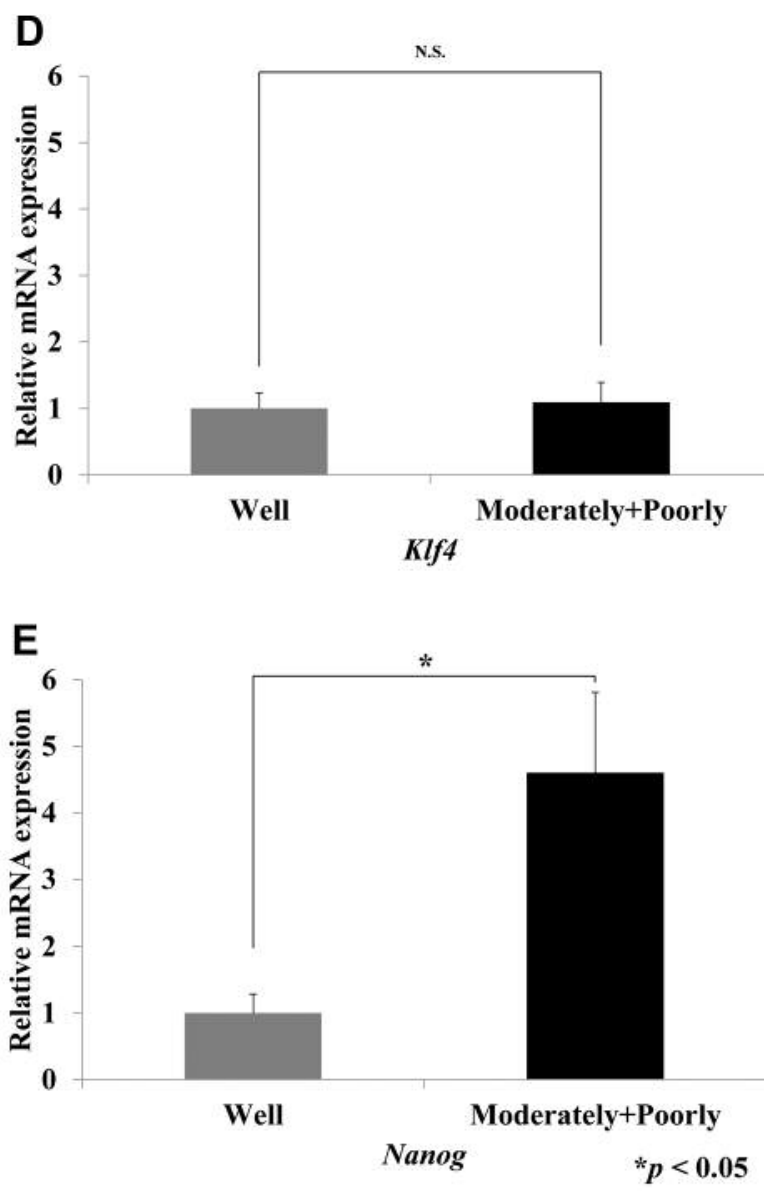

Figure 1. Expression levels of iPS-related genes in well-, moderatelyand poorly-differentiated samples in clinical SCC samples. The mRNA expression levels of (A) Oct3/4, (B) Sox2, (C) c-Myc, (D) Klf4, and (E) Nanog in cancerous tissues relative to normal tissues were evaluated using quantitative real-time polymerase chain reaction (PCR).

apoptosis, cell metabolism, and cell adhesion and selfrenovation of tumor stem cells (29). It is reported that c-Myc overexpression is related to malignant transformation of oral lichen planus to oral SCC (30). On the other hand, quantitative expression of c-Myc in oral SCC had no statistically significant relationship with clinical and pathological parameters (31). Klf4 is a transcription factor 

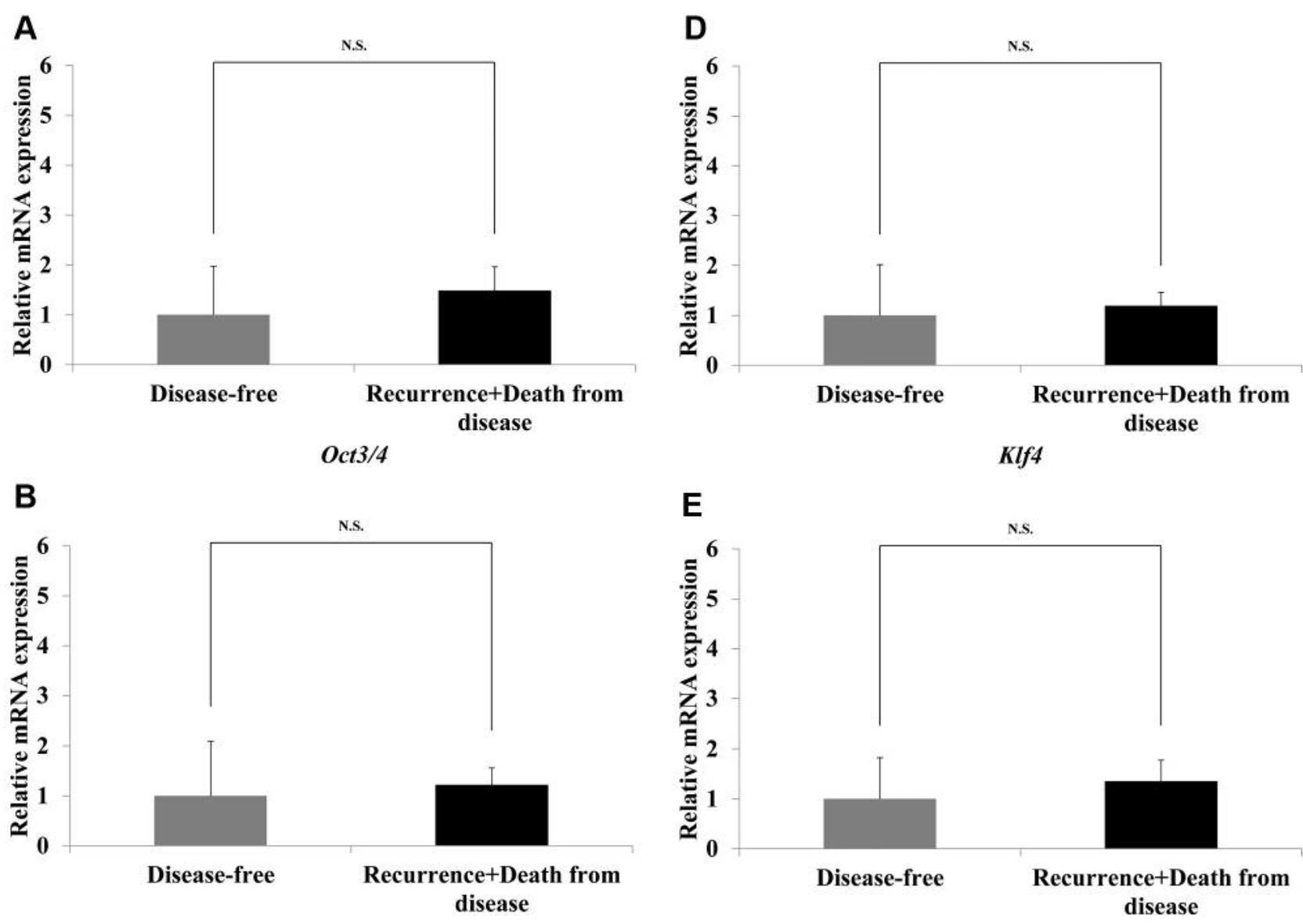

Sox 2
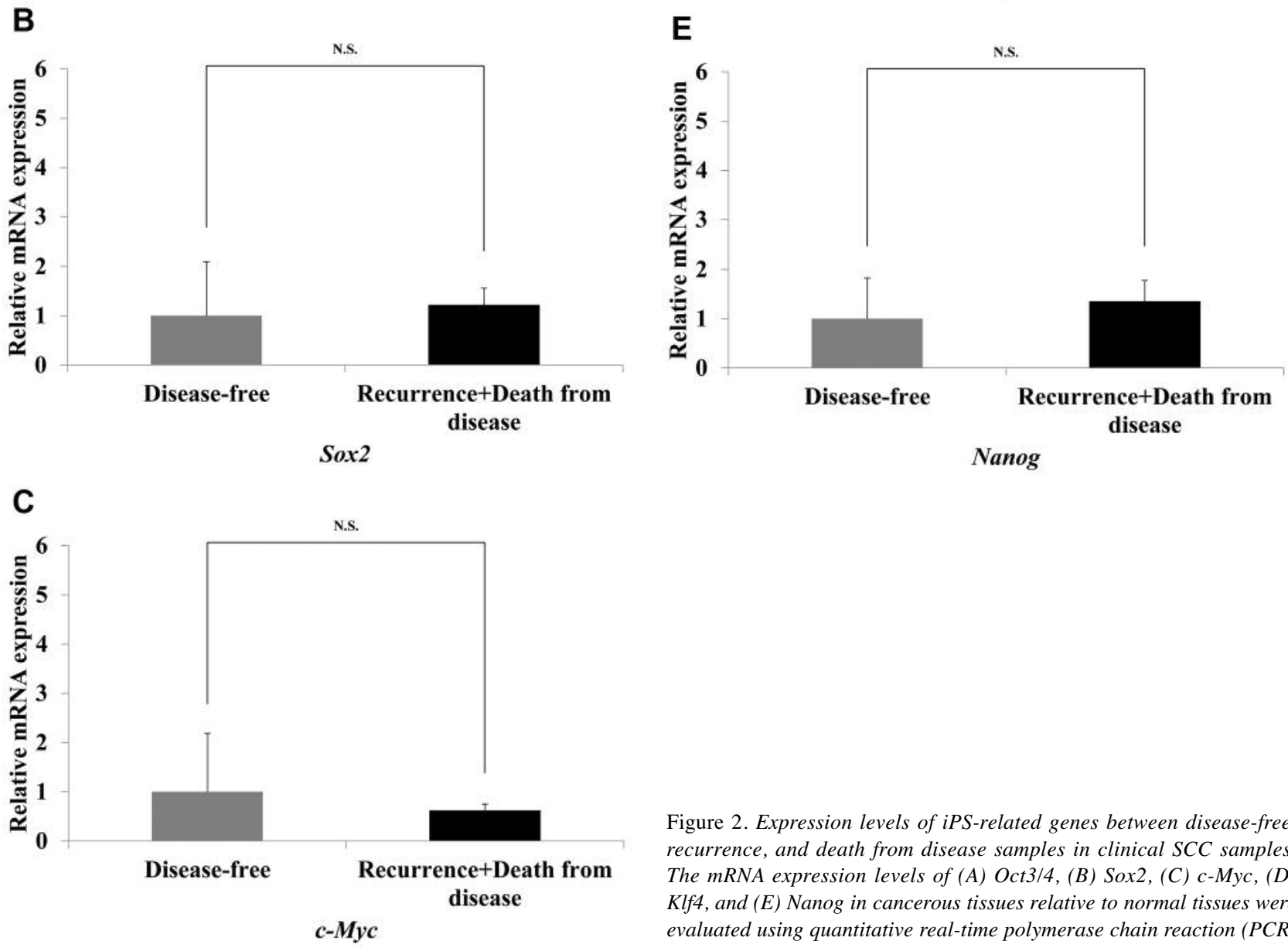

Figure 2. Expression levels of iPS-related genes between disease-free, recurrence, and death from disease samples in clinical SCC samples. The mRNA expression levels of (A) Oct3/4, (B) Sox2, (C) c-Myc, (D) $K l f 4$, and $(E)$ Nanog in cancerous tissues relative to normal tissues were evaluated using quantitative real-time polymerase chain reaction (PCR)

associated with both tumor suppression and oncogenesis, meaning it possesses opposing roles in human cancers (3235). In head and neck SCC, expression of Klf4 can predict poor prognosis and confer progression, for example through tumorigenic, migratory and invasive abilities (32). However, in breast cancer cells, Nanog was found to stimulate the

growth and metastasis of breast cancer cells, whereas Klf4 inhibited these processes (33). It should be noted that these reports are a small number of many studies focusing on one to three iPS-related genes, and that the relationship between iPS-related genes and prognosis remains controversial in many cancers. 

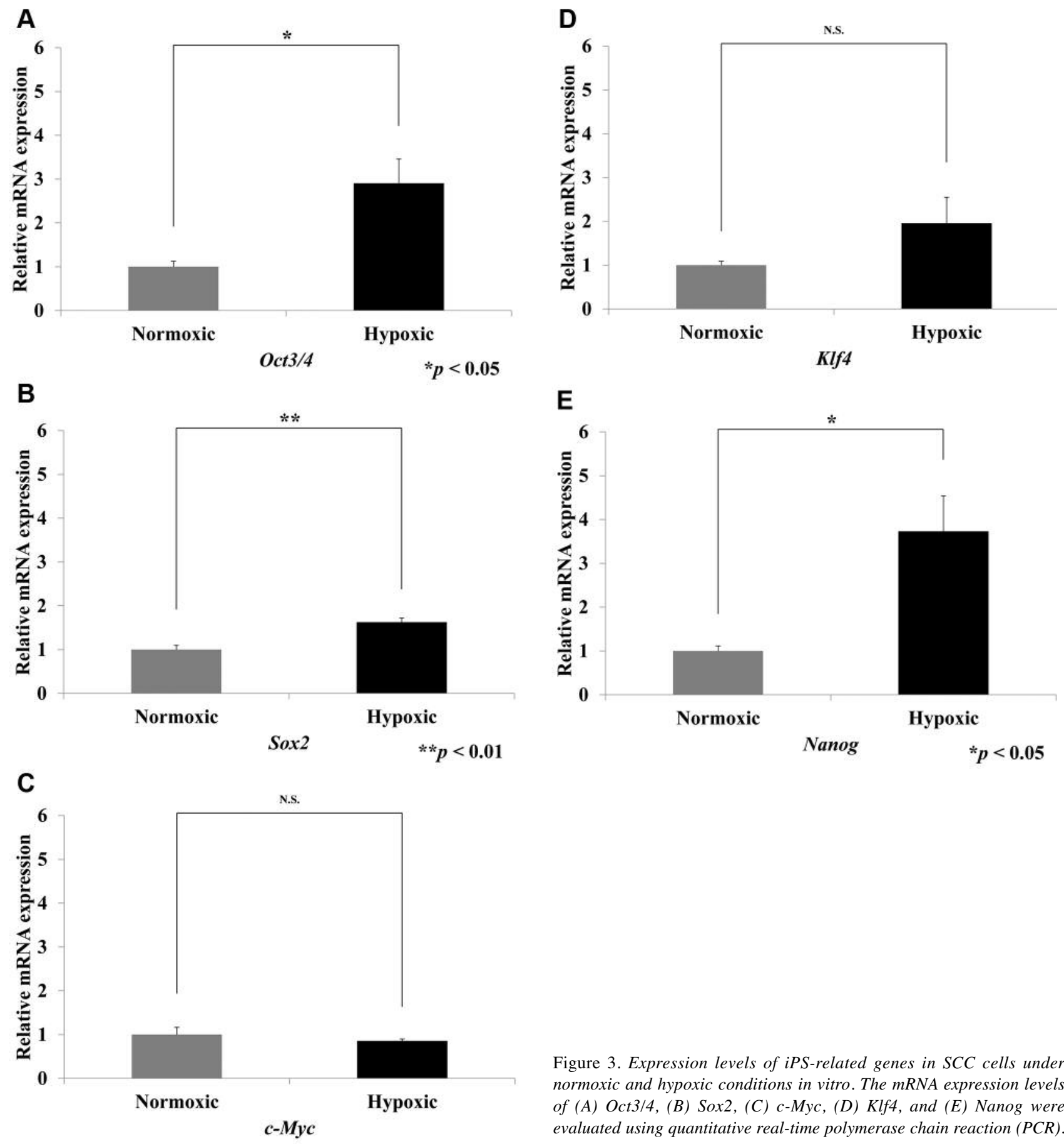

Figure 3. Expression levels of iPS-related genes in SCC cells under normoxic and hypoxic conditions in vitro. The mRNA expression levels of (A) Oct3/4, (B) Sox2, (C) c-Myc, (D) Klf4, and (E) Nanog were evaluated using quantitative real-time polymerase chain reaction (PCR).

Cancerization involves multiple and multi-step genetic alterations that lead to genomic instability and disordered cell growth due to oncogene overexpression and subexpression of tumor suppressor genes and other genetic and/or epigenetic alterations. Cancer cells, especially in poorly-differentiated or undifferentiated tumors, are similar to undifferentiated embryonic cells. Overexpression of Oct3/4, Sox2, c-Myc, and

Nanog is reported in poorly-differentiated tumors compared with well-differentiated tumors in breast cancers, glioblastomas and bladder carcinomas (36). In the present study, we showed that expression levels of Oct3/4, Sox 2 and Nanog were significantly increased in moderately- and poorly-differentiated samples compared with welldifferentiated samples. 
Hypoxia is common in solid tumors, including SCCs, and can increase the invasiveness and metastatic ability of tumor cells (1). It has been suggested that hypoxic conditions $(5 \%$ oxygen) can improve the efficiency of iPS cell generation from mouse and human somatic cells (13). Furthermore, culture in normoxic conditions ( $20 \%$ oxygen) was shown to decrease human ESC proliferation and result in significantly reduced expression of Oct $3 / 4$, Sox 2 and Nanog compared with hypoxic conditions (5\% oxygen) (37). In the present study, we showed that expression levels of Oct $3 / 4$, Sox 2 and Nanog were significantly increased in the hypoxic condition compared with the normoxic condition. Oct $3 / 4$, Sox 2 and Nanog may therefore be responsible for the undifferentiated potency and hypoxic conditions observed in oral SCC.

In conclusion, we revealed that expression levels of Oct3/4, Sox 2, and Nanog were increased in oral SCC cells under hypoxic culture in vitro and in moderately- and poorly-differentiated oral SCC clinical samples. We will continue to investigate the relationship between stemness factors and patient prognosis in our future studies.

\section{Conflicts of Interest}

The Authors declare that no conflicts of interest exist.

\section{Acknowledgements}

This study was funded by Hyogo Prefecture Health Promotion Association and Takeda Science Foundation. The funders had no role in the preparation of the study. This work was supported by Hyogo Science and Technology Association and JSPS KAKENHI (Grant Number 16K20575).

\section{References}

1 Teppo S, Sundquist E, Vered M, Holappa H, Parkkisenniemi J, Rinaldi T, Lehenkari P, Grenman R, Dayan D, Risteli J, Salo T and Nyberg P: The hypoxic tumor microenvironment regulates invasion of aggressive oral carcinoma cells. Exp Cell Res 319: 376-389, 2013.

2 Alsat E, Wyplosz P, Malassine A, Guibourdenche J, Porquet D, Nessmann C and Evain-Brion D: Hypoxia impairs cell fusion and differentiation process in human cytotrophoblast, in vitro. $\mathrm{J}$ Cell Physiol 168: 346-353, 1996.

3 Sahai A, Mei C, Zavosh A and Tannen RL: Chronic hypoxia induces LLC-PK1 cell proliferation and dedifferentiation by the activation of protein kinase C. Am J Physiol 272: F809-815, 1997.

4 Azuma Y, Chou SC, Lininger RA, Murphy BJ, Varia MA and Raleigh JA: Hypoxia and differentiation in squamous cell carcinomas of the uterine cervix: pimonidazole and involucrin. Clin Cancer Res 9: 4944-4952, 2003.

5 Ghafar MA, Anastasiadis AG, Chen MW, Burchardt M, Olsson LE, Xie H, Benson MC and Buttyan R: Acute hypoxia increases the aggressive characteristics and survival properties of prostate cancer cells. Prostate 54: 58-67, 2003.
6 Jogi A, Ora I, Nilsson H, Lindeheim A, Makino Y, Poellinger L, Axelson $\mathrm{H}$ and Pahlman S: Hypoxia alters gene expression in human neuroblastoma cells toward an immature and neural crestlike phenotype. Proc Nat Acad Sci USA 99: 7021-7026, 2002.

7 Helczynska K, Kronblad A, Jogi A, Nilsson E, Beckman S, Landberg $G$ and Pahlman $S$ : Hypoxia promotes a dedifferentiated phenotype in ductal breast carcinoma in situ. Cancer Res 63: 1441-1444, 2003.

8 Reya T, Morrison SJ, Clarke MF and Weissman IL: Stem cells, cancer, and cancer stem cells. Nature 414: 105-111, 2001.

9 Takahashi K and Yamanaka S: Induction of pluripotent stem cells from mouse embryonic and adult fibroblast cultures by defined factors. Cell 126: 663-676, 2006.

10 Takahashi K, Tanabe K, Ohnuki M, Narita M, Ichisaka T, Tomoda K and Yamanaka S: Induction of pluripotent stem cells from adult human fibroblasts by defined factors. Cell 131: 861$872,2007$.

11 Suva ML, Riggi N and Bernstein BE: Epigenetic reprogramming in cancer. Science (New York, NY) 339: 1567-1570, 2013.

12 Okita K, Ichisaka T and Yamanaka S: Generation of germlinecompetent induced pluripotent stem cells. Nature 448: 313-317, 2007.

13 Yoshida Y, Takahashi K, Okita K, Ichisaka T and Yamanaka S: Hypoxia enhances the generation of induced pluripotent stem cells. Cell Stem Cell 5: 237-241, 2009.

14 Mimeault $\mathrm{M}$ and Batra SK: Hypoxia-inducing factors as master regulators of stemness properties and altered metabolism of cancer- and metastasis-initiating cells. J Cell Mol Med 17: 3054, 2013.

15 Sugimoto K, Yoshizawa Y, Yamada S, Igawa K, Hayashi Y and Ishizaki H: Effects of hypoxia on pluripotency in murine iPS cells. Microsc Res Tech 76: 1084-1092, 2013.

16 Takeda D, Hasegawa T, Ueha T, Imai Y, Sakakibara A, Minoda M, Kawamoto T, Minamikawa T, Shibuya Y, Akisue T, Sakai Y, Kurosaka $\mathrm{M}$ and Komori T: Transcutaneous carbon dioxide induces mitochondrial apoptosis and suppresses metastasis of oral squamous cell carcinoma in vivo. PloS One 9: e100530, 2014.

17 Takeda D, Hasegawa T, Ueha T, Sakakibara A, Kawamoto T, Minamikawa T, Sakai Y and Komori T: Decreased mitochondrial copy numbers in oral squamous cell carcinoma. Head Neck 38 : 1170-1175, 2016.

18 Saiki Y, Ishimaru S, Mimori K, Takatsuno Y, Nagahara M, Ishii $\mathrm{H}$, Yamada $\mathrm{K}$ and Mori M: Comprehensive analysis of the clinical significance of inducing pluripotent stemness-related gene expression in colorectal cancer cells. Ann Surg Oncol 16: 2638-2644, 2009.

19 Galatro TF, Uno M, Oba-Shinjo SM, Almeida AN, Teixeira MJ, Rosemberg S and Marie SK: Differential expression of ID4 and its association with TP53 mutation, SOX2, SOX4 and OCT-4 expression levels. PloS One 8: e61605, 2013.

20 Ravindran G, Sawant SS, Hague A, Kingsley K and Devaraj H: Association of differential beta-catenin expression with Oct-4 and Nanog in oral squamous cell carcinoma and their correlation with clinicopathological factors and prognosis. Head Neck 37: 982-993, 2015.

21 Chiou SH, Yu CC, Huang CY, Lin SC, Liu CJ, Tsai TH, Chou $\mathrm{SH}$, Chien CS, Ku HH and Lo JF: Positive correlations of Oct4 and Nanog in oral cancer stem-like cells and high-grade oral squamous cell carcinoma. Clin Cancer Res 14: 4085-4095, 2008. 
22 Chiou SH, Wang ML, Chou YT, Chen CJ, Hong CF, Hsieh WJ, Chang HT, Chen YS, Lin TW, Hsu HS and Wu CW: Coexpression of Oct4 and Nanog enhances malignancy in lung adenocarcinoma by inducing cancer stem cell-like properties and epithelial-mesenchymal transdifferentiation. Cancer Res 70: 10433-10444, 2010.

23 Shimada Y, Okumura T, Sekine S, Moriyama M, Sawada S, Matsui K, Yoshioka I, Hojo S, Yoshida T, Nagata T, Fukuoka J and Tsukada K: Expression analysis of iPS cell - inductive genes in esophageal squamous cell carcinoma by tissue microarray. Anticancer Res 32: 5507-5514, 2012.

24 Palla AR, Piazzolla D, Alcazar N, Canamero M, Grana O, Gomez-Lopez G, Dominguez O, Duenas M, Paramio JM and Serrano M: The pluripotency factor NANOG promotes the formation of squamous cell carcinomas. Sci Rep 5: 10205, 2015.

25 Watanabe M, Ohnishi Y, Inoue H, Wato M, Tanaka A, Kakudo K and Nozaki M: NANOG expression correlates with differentiation, metastasis and resistance to preoperative adjuvant therapy in oral squamous cell carcinoma. Oncol Lett 7: 35-40, 2014.

26 Lee SH, Oh SY, Do SI, Lee HJ, Kang HJ, Rho YS, Bae WJ and Lim YC: SOX2 regulates self-renewal and tumorigenicity of stem-like cells of head and neck squamous cell carcinoma. Br J Cancer 111: 2122-2130, 2014.

27 Wang Q, He W, Lu C, Wang Z, Wang J, Giercksky KE, Nesland JM and Suo Z: Oct $3 / 4$ and Sox 2 are significantly associated with an unfavorable clinical outcome in human esophageal squamous cell carcinoma. Anticancer Res 29: 1233-1241, 2009.

28 Lengerke C, Fehm T, Kurth R, Neubauer H, Scheble V, Muller F, Schneider F, Petersen K, Wallwiener D, Kanz L, Fend F, Perner S, Bareiss PM and Staebler A: Expression of the embryonic stem cell marker SOX2 in early-stage breast carcinoma. BMC Cancer 11: 42, 2011.

29 Perez-Sayans M, Suarez-Penaranda JM, Pilar GD, BarrosAngueira F, Gandara-Rey JM and Garcia-Garcia A: What real influence does the proto-oncogene c-myc have in OSCC behavior? Oral Oncol 47: 688-692, 2011.

30 Segura S, Rozas-Munoz E, Toll A, Martin-Ezquerra G, Masferrer E, Espinet B, Rodriguez M, Baro T, Barranco C and Pujol RM: Evaluation of MYC status in oral lichen planus in patients with progression to oral squamous cell carcinoma. Br J Dermatol 169: 106-114, 2013.
31 Perez-Sayans M, Suarez-Penaranda JM, Padin-Iruegas E, Gayoso-Diz P, Reis-De Almeida M, Barros-Angueira F, GandaraVila P, Blanco-Carrion A and Garcia-Garcia A: Quantitative determination of c-myc facilitates the assessment of prognosis of OSCC patients. Oncol Rep 31: 1677-1682, 2014.

32 Tai SK, Yang MH, Chang SY, Chang YC, Li WY, Tsai TL, Wang YF, Chu PY and Hsieh SL: Persistent Kruppel-like factor 4 expression predicts progression and poor prognosis of head and neck squamous cell carcinoma. Cancer Sci 102: 895-902, 2011.

33 Nagata T, Shimada Y, Sekine S, Hori R, Matsui K, Okumura T, Sawada S, Fukuoka J and Tsukada K: Prognostic significance of NANOG and KLF4 for breast cancer. Breast Cancer (Tokyo, Japan) 21: 96-101, 2014.

34 Tetreault MP, Wang ML, Yang Y, Travis J, Yu QC, Klein-Szanto AJ and Katz JP: Klf4 overexpression activates epithelial cytokines and inflammation-mediated esophageal squamous cell cancer in mice. Gastroenterology 139: 2124-2134, 2010.

35 Tian Y, Luo A, Cai Y, Su Q, Ding F, Chen H and Liu Z: MicroRNA-10b promotes migration and invasion through KLF4 in human esophageal cancer cell lines. J Biol Chem 285: 79867994, 2010

36 Ben-Porath I, Thomson MW, Carey VJ, Ge R, Bell GW, Regev $A$ and Weinberg RA: An embryonic stem cell-like gene expression signature in poorly differentiated aggressive human tumors. Nat Genet 40: 499-507, 2008.

37 Forristal CE, Wright KL, Hanley NA, Oreffo RO and Houghton FD: Hypoxia inducible factors regulate pluripotency and proliferation in human embryonic stem cells cultured at reduced oxygen tensions. Reproduction (Cambridge, England) 139: 8597, 2010 